\title{
Factors associated with high Cesarean deliveries in China and Brazil - A Call for reducing elective surgeries in moving towards Universal Health Coverage
}

\author{
Xiaohui Hou ${ }^{1}$, Noor Sabah Rakhshani ${ }^{2}$, Roberto I unes ${ }^{1}$ \\ 1. Health, Nutrition and Population Global Practice, World Bank, Washington, USA. 2. Johns Hopkins Bloomberg School of \\ Public Health, J ohns Hopkins University, Baltimore, USA. \\ Correspondence: Xiaohui Hou. Address: Health, Nutrition and Population Global Practice, World Bank, 1818 H. Street, \\ NW, Washington DC, 20433, USA. E-mail: xhou@worldbank.org
}

Received: December 22, 2013

Accepted: March 2, 2014

Online Published: April 18, 2014

DOI : $10.5430 /$ jha.v3n5p67

URL: http://dx.doi.org/10.5430/jha.v3n5p67

\section{Abstract}

Background: Annually 6.2 million unnecessary Cesarean Deliveries (CD) are performed globally. Such high unnecessary $\mathrm{CD}$ rate is a concern not only due to the additional financial burden it places on the health system, but also because the quality of care could be compromised. There is an even more imperative need to reduce elective surgeries in moving towards the Universal Health Coverage (UHC), to ensure the ever stretched resources are effectively channeled for the best health outcomes.

Methods: The paper uses a case study method. China and Brazil were selected primarily due to their alarmingly high number and percentage of the CD rate. Systematic literature review was conducted and the analyses were structured based on the framework "Determinants of High Cesarean Delivery Rates", developed by the authors.

Results: In China and Brazil, cultural belief, fear of labor pain and patient's perception regarding quality of care may play a role in the patient's preference for CD but these perceptions are shaped by their health care providers as well. The principal-agent relation comes into play as the health professionals can modify perceived needs of their patients. Availability of health insurance to mothers, physicians' preference for convenient working hours, and payment incentives for performing higher yielding Cesarean procedures are driving the high CD rate phenomena in China and Brazil.

Understand the social determinants of $\mathrm{CD}$ and using various instruments to change women's perceptions of birthing options and physicians' behaviors are critical in managing the $\mathrm{CD}$ rate.

Conclusion: In the context of the rapid movement towards UHC, the evidence presented in this paper supports the call for implementing complementary policy interventions and regulation to ensure minimal efficiency loss due to resources being diverted to unnecessary procedures or hospital stays.

\section{Key words}

Elective surgery, Cesarean delivery, Universal health coverage, China, Brazil 


\section{Introduction}

The collective view of Universal Health Coverage (UHC) is gaining momentum among health planners and policy makers, as countries invest in the health of their populations. These countries face, however, major challenges on their paths towards UHC, such as the ones posed by demographic and epidemiological transitions, by the increasing cost of medical procedures in the wake of technological advancement, and by the growing demand for health services as citizens become better informed of their rights and needs. The progress towards UHC requires, therefore, policy and implementation strategies that ensure that limited resources are effectively channeled for the best health outcomes. In this sense, the escalating cost of unnecessary medical procedures, without the added benefits of improving the quality of life, constitutes another obstacle in realizing UHC.

While there are several examples of unnecessary medical procedures - such as repeated Magnetic Resonance Imaging (MRI) and Computed Tomography (CT) scanning for lower back pain ${ }^{[1]}$, or Vertebroplasty procedures ${ }^{[2]}$ - the $35 \%-50 \%$ Cesarean delivery (CD) rates observed in some middle income countries represents an alarming phenomenon that deserves particular attention.

Birthing is a natural process. High CD rates are a concern not only due to the financial burden they pose on the health care system, but also because they result in greater short and long term morbidity of mothers and infants ${ }^{[3-5]}$. In most cases, CD also compromises the quality of care provided to mothers and children due to heavy reliance on prophylactic use of antibiotics for mothers ${ }^{[6]}$ and failure to initiate early breastfeeding of infants ${ }^{[7]}$. More recent research also suggests that mothers delivering by CD are more likely to suffer from Post-Partum Depression (PPD) compared to mothers who had vaginal delivery (VD) ${ }^{[8]}$. According to the World Health Organization (WHO), national CD rates in the range of $10 \%-15 \%$ of all the births ensure optimal benefits to mother and child, preventing maternal and neonatal mortality ${ }^{[9]}$. Cesarean delivery rates above this level have no added health benefits; in fact they may bring unnecessary risks due to the more invasive nature of the technique and higher health care costs.

Despite this, Cesarean deliveries have reached epidemic proportions, and it is estimated that each year 6.2 million unnecessary CDs are performed globally at a total cost of $\$ 2.32$ billion ${ }^{[10]}$. No single factor can explain the rising CD rates. Both population preferences and provider behaviors have shown to determine this phenomenon ${ }^{[11]}$. Demand side factors like higher socio-economic status, higher maternal age and the presence of health insurance are strongly associated with high CD rates ${ }^{[12-14]}$. Similarly, health care providers' practice preferences and medical judgment, fear of mal-practice litigation and payment incentives ${ }^{[13,15]}$ are also important in determining the choice of birthing procedure.

This paper has two main objectives: the first is to analyze the causes for high CD rate, from both demand and supply perspectives, as evidenced in the literature. The analyses focuses on two case studies: China and Brazil, as their large populations and high rates of Cesarean sections make these two countries account for $50 \%$ of the total unnecessary Cesarean deliveries performed in the world ${ }^{[10]}$. The second objective of the paper is to summarize the interventions aimed at reducing the CD rate presented by the literature, and discuss their evaluations.

The paper is organized as follows. Section 2 describes the case study method employed in the paper; Section 3 and section 4 discuss the China and Brazil cases respectively. Section 5 concludes the case studies and presents a summary of the literature on policy recommendations to reduce unnecessary Cesarean delivery and the last section links with the current UHC movement and calls for complementary polices to reduce the unnecessary health resources waste on elective surgeries.

\section{A case study method}

The paper uses a case study method. The case study method is particularly insightful when the objective of the analysis is to explore in greater descriptive detail the causal links between variables of interest ${ }^{[16]}$. In this case, we are interested in the 
link between various factors related to patients and the health system and the unnecessary Cesarean delivery (dependent variable of interests). Quantitatively, such analysis will require sufficient variation both at the individual levels (to control for education, age, residence and other family and peer related variables) and system level (to control for physician's payment incentive, delivery system). Such analysis can suffer from unobserved variable bias unless the analysis uses some identification strategy to control for unobserved factors. Due to lack of data with such proper identification, we chose to use case study methods and review related literatures aiming for a more comprehensive yet more qualitative understanding of the issue.

\subsection{Case selection}

There are a large number of units of analysis (country cases) that may be used to explore the linkages between the various factors and high rate of unnecessary Cesarean delivery. We focus on developing countries because there is a clear need to channel the limited resources in an effective and efficient manner as developing countries implement health policies aimed at increasing health benefits and coverage to their populations. It is not such a serious problem in low income countries which are still struggling to increase institutional delivery (delivery in the health facilities, as opposed to delivery at home). In most developed countries, the rise in the rate of CD is slowing down; the rate of CD is even stabilizing in some countries ${ }^{[17]}$. However, in many middle-income countries where the recent economic development has significantly improved population's access to health services, the CD rates are alarmingly high. Among these middle income countries, China and Brazil stand out. Some studies have reported CD rates as high as $70 \%-80 \%{ }^{[8]}$ in some parts of China and Brazil. China contributes to the largest number of unnecessary CDs: in 2008, almost two million unnecessary procedures were performed at an annual estimated total cost of approximately $\$ 326.5$ million, accounting for $31.8 \%$ of the global unnecessary CDs performed annually ${ }^{[10]}$. The $48 \%$ CD rate observed in Brazil in 2008 represents more than one million unnecessary CDs annually, or $16.3 \%$ of the unnecessary CDs performed globally. It is estimated that these procedures cost the Brazilian economy approximately $\$ 226.8$ million annually ${ }^{[10]}$. What is being observed in China and Brazil is also a concern for other developing countries, particularly to middle-income countries like Mexico, which ranks the fourth in the world in the number of unnecessary CDs ${ }^{[10]}$, or Turkey, which is also experiencing a steep increase in CD rates and continues to have one of the highest rates in Europe.

\subsection{Case study framework}

To understand the relationship between high CD rate and the associated supply (health systems) and demand (population characteristics) factors, two frameworks were consulted, namely Andersen \& Aday "Behavior Model and Access to Health Care Framework" ${ }^{[18,19]}$ and the diagnosis tree model in Roberts et al.'s "Getting the Reform Right” ${ }^{20]}$. These two frameworks were selected for their relevance to the study objectives and simplicity of use. The determinants of a health outcome can be identified as a series of variables incorporating the 1) health care system, representing the supply-side of health services, and 2) population characteristics or the demand for health services. The components of the health care system like setup (public and private) and level (secondary and tertiary) are not shown in the framework but evaluated in this paper for their association with the high CD rates because they are embedded in the payment systems to physicians. Population characteristics encompass the preference of the women and the enabling factors available to them, and are evaluated in detail in this study. The prevalent culture, social network of family and friends as well as their sociodemographic status like education and area of residence shape women's preferences for mode of delivery. The enabling factors like higher household income and health insurance which cover a given procedure, namely CD, are also strong determinants of the choice of health services uptake and their association has been noted in this study. We use this analytical framework to guide our analysis in the following two case studies and interventions. These demand and supply factors are summarized in Figure 1 below.

An extensive literature review was conducted online using global search databases such as PubMed, Scopus and Google scholar to identify peer reviewed publications and reports by prominent organizations like WHO and the World Bank. Keywords like Cesarean section, birthing, surgical obstetrics, vaginal delivery and Cesarean delivery, China and Brazil, were used to identify publications published in English language in the past fifteen years. First the titles were screened to 
select the studies; in the second step the abstracts were read to select the relevant studies. In the third step, selected papers and reports were reviewed in detail to identify the factors associated with increased Cesarean sections and the interventions to reduce it.

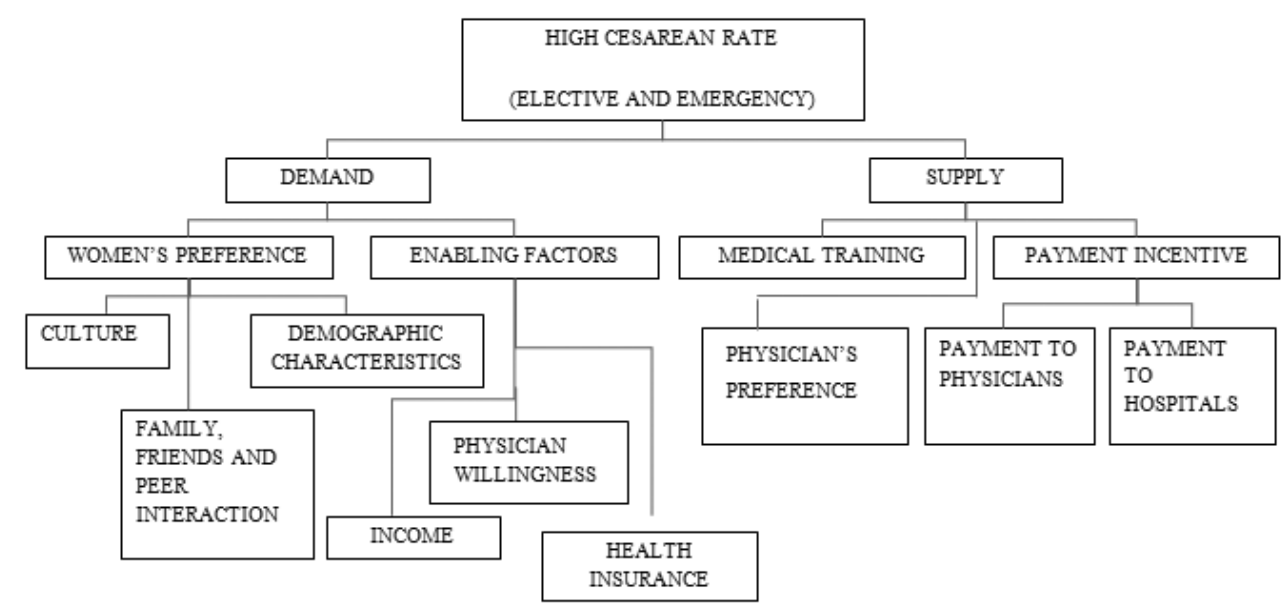

Figure 1. Determinants of high cesarean delivery rates

\section{The case of China}

In China, the world's most populous nation, nearly 50 percent of all births are carried out by CDs. Though China has achieved significant progress in terms of health insurance coverage and plans to achieve universal coverage by $2020{ }^{[21]}$, the country is facing the challenge of continuing to improve insurance coverage and increase its benefit package, while at the same time preventing cost escalation. A recently published paper shows the trend of CD rates in China from 1988 to 2008, indicating that the CD rate has increased from 20\% in 1998 to over $60 \%$ in 2008 in urban areas and similar magnitude of increase in rural areas, independent of the socio-economic status of rural regions ${ }^{\text {[22] }}$.

The evidence regarding the association between the presence of health insurance and high CD rate and its increase is mixed. Some studies have identified the presence of health insurance as a highly significant determinant of the rising rates of both unplanned Cesarean delivery, as well as of Cesarean delivery on maternal request ${ }^{[23]}$. Women with health insurance plans that cover the cost of delivery are more likely to give birth by Cesarean section, and this occurs mostly by mother's request ${ }^{[13]}$. A study in Taiwan ${ }^{[24]}$ found that after the implementation of the National Health Insurance (NHI) scheme, the likelihood that a woman would choose primary Cesarean delivery increased by four to five times compared to the pattern observed prior to the NHI. However, it seems that the lack of health insurance is not a deterring factor to seek CD among Chinese women in Mainland China. According to Xiao et al. ${ }^{[25]}$, mothers without health insurance and thus incurring with the total cost of the delivery have similar rates of $\mathrm{CD}$ as insured mothers ${ }^{[25]}$. Feng et al. ${ }^{[2]}$ also report that the large variation in CD rate in mainland China is independent of the individual's income, health insurance or education. They state place of residence as a major factor, since urban women had a higher CD rate compared to rural women of same educational status, which points to the availability of technologically advance obstetrical services as a possible driving factor.

Several factors explain the increase in the incidence of delivery associated complications, and some of them are directly or indirectly linked with social and economic development. For example, gestational diabetes and excess nutrients during pregnancy can lead to "large for gestational age” fetus; increasing maternal age and the use of assisted conceptive methods to induce pregnancy can also lead to complications during delivery. From a medical perspective, some mothers may fear the risk of perineal trauma (anal and stress uninary incontinence) and pelvic floor muscle weakness after vaginal delivery and later possible adverse effects on sex life. These all increase the demand of C-section. Cultural factors also contribute to 
women's choice of delivery methods - e.g. traditional and cultural believes of mother may influence them to seek CD to give birth on auspicious days ${ }^{[14,26]}$ or to avoid ominous days ${ }^{[27]}$. However, these demand-side factors would not be sufficient to explain the large number of CD performed annually.

The principal-agent relationship between patients and doctors seem to play a more important role, as the latter can modify the perceived needs of the former. Women's fear of natural labor and the perception that CD is safest for the infant is shared by a large number of women, but these beliefs are in part shaped by the information provided by health professionals ${ }^{[28]}$. Though there is not published evidence from Mainland China, the evidence in Taiwan shows that women in the early part of their pregnancy are more likely to prefer vaginal delivery but that preference changes in the later stages of their pregnancy after repeated interaction with their physicians ${ }^{[29]}$.

Recent published literature also point to payment incentives to providers and institutions as one of the main factors driving the CD epidemic ${ }^{[30]}$. In China, the budget support coming from the government to public hospitals have been reduced significantly in the past two decades. As a result, in order to remain financially sustainable, public hospitals have to find alternative revenue-generating mechanisms. One of the methods is to link physician's bonuses with the revenue they brought to the departments and hospitals. That is, the more "productive" the physicians are, the more revenue he/she generates, the higher bonuses he/she can get. Under such incentive and the predominant fee-for-service payment mechanism, physicians are more likely to take more "revenue generating" procedures, such as those that involve more medical technology for diagnosis and treatment, and prescribe more expensive medications, as the price of these procedures and prescriptions tend to provide higher margins ${ }^{[31,32]}$. Compared with vaginal delivery, Cesarean delivery has higher returns, not only because of the longer hospital stay associated with delivery by Caesarean section, but also because the antibiotics and other medicines involved in the procedure that also generate higher revenues to the hospitals. Furthermore, natural childbirth is a longer process and requires continuous monitoring and custody of the mother and the fetus. While human resource costs are relatively high for natural birth, fees are much lower than the CD. In some countries, midwives play an important role in providing a continuum of care needed by pregnant women, delivery and their newborns, thus reducing these costs. In China, however, the lack of specific midwives professional positions and mid-wife specific job promotion paths has generated a great shortage of midwives and a degradation of their skills, which has increased the cost of human resources of natural delivery.

\section{The case of Brazil}

Cesarean delivery rates more than doubled in Brazil during the 1970s: from less than $15 \%$ in 1970 to more than $30 \%$ in $1980^{[33,34]}$. This phenomenon can be explained by several factors such as: i) the rapid growth of the economy and associated rising middle class and urbanization process; ii) the expansion of the existing social security system; iii) requests for sterilization by tubal ligation; and iv) payment structure that provided physicians a higher fee for CDs. In order to curb the latter, the social security system in 1980 started to pay physicians the same fee for both CD and VD. However, because hospitals continued to be able to charge twice as much for a CD, compared to a VD, the rate of Cesarean sections continued to rise during the 1980s, and by 1984 CD rates were just below $40 \%$, rising alarm among public health professionals ${ }^{[35]}$. The rates plateaued during the 1990s remaining stable till 2000 when they started to rise again ${ }^{\text {[33] }}$. Although it is not clear why the stabilization observed in the 1990s occurred, it could be argued that it was due to the contracts and changes that were occurring in the private insurance market.

As Figure 2 shows, national Cesarean rates increased almost 32\% between 2000 and 2010, from 38\% to 52\%, with higher incidence rates observed in the richer regions of the country (Southeast, South and Central), where private insurance coverage is more prevalent. That figure also shows a marked difference between richer and poorer regions, with the former presenting CD rates averaging around 56\% and the poorer areas of the country with CD rates closer to $40 \%$. 
Figure 2. Cesarean section rates in Brazil, 2000-2010, by geographic region

Note. Data source: "Basic Health Indicators in Brazil: Concepts and Applications” (“Indicadores básicos para a saúde no Brasil: conceitos e aplicações"), 2010.

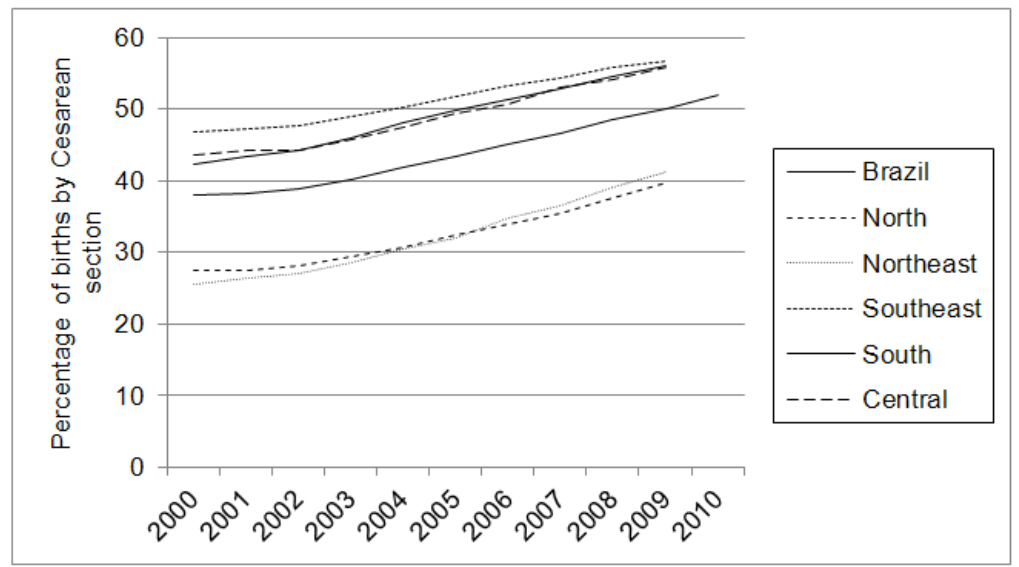

Since the mid-1990s, $90 \%$ of the births are institutional, and $80 \%$ of the deliveries are financed by the Brazilian national health system, the Sistema Único de Saúde (SUS) ${ }^{[36]}$. Data for 2006 indicate that the overall rate of Cesarean sections in the SUS was $30.1 \%{ }^{[37]}$, ranging from $18.9 \%{ }^{[32]}$ to $36 \%{ }^{[36,38]}$, with some studies reporting rates as high as $43 \%$ throughout the years ${ }^{[39]}$.

Even though these rates are twice the level recommended by the WHO, they are significantly smaller than those observed in the private sector with rates of CDs ranging from $23 \%{ }^{[36]}$ to $67 \%{ }^{[40]}$. Cesarean delivery rate almost doubles among women seeking care from private providers compared to women delivering in the public sector ${ }^{[39]}$.

Cultural factors also help explain the high CD rates in Brazil. Normal, vaginal delivery in Brazil is seen as invasive (episiotomy) and traumatic ${ }^{[41]}$, and of lower quality of care, a view held both by patients from the SUS and from the private sector. The perceived need for CD is shaped by the cultural belief that delivery by Cesarean section is a method of choice for women of higher social status, as well as higher quality of care ${ }^{[42-44]}$. Among patients seeking maternal services in the public sector, mothers with higher education and economic status and of Caucasian origin are more likely to deliver by $\mathrm{CD}^{[45]}$. The print media and women's magazines also seem to influence patients' preferences by hinting the favorable aspects of $\mathrm{CD}$ rather than reporting the long term negative consequences of Cesarean delivery ${ }^{[46]}$. These findings suggest the presence of demand-side pressures that promote higher $\mathrm{CD}$ rates.

However, research shows that early in their pregnancy a large proportion of women in Brazil have preferences for VD ${ }^{[47]}$. In a recent major study conducted in four large cities, $72.3 \%$ of women attending the private sector and $79.6 \%$ in the public sector, had a preference for VD, but by the last trimester, many of these women changed their preference after repeated interaction with and persuasion by their providers ${ }^{[40]}$. Similarly, $70 \%$ of the women attending the private sector in the State of Rio de Janeiro had a preference for VD, but $90 \%$ of them ended having a CD after interaction with their health providers ${ }^{[48]}$. While changes in preference that occur in the course of pregnancy might be due to unexpected complications, they can also be due to the unbalanced power relationship that exists between patients and physicians which renders the former to submit to the decision of the latter.

Among the several factors that explain the physicians' preference for CD, two seem to be more significant: a physician's working hours preferences and payment incentives especially in the private sector ${ }^{[37]}$. In the private sector, physicians perform CDs on times and days that are most suitable to them ${ }^{[36]}$. The majority of CDs are carried out during the weekday and routine working hours and, in the private sector, almost never on weekends or at odd hours ${ }^{[32]}$. While a doctor can perform a Cesarean section in an hour, a VD can extend for several hours, requiring doctors to work late or odd hours therefore making the former the method of choice by most physicians. In Brazil, even though physicians continue to receive the same fee for VDs and CDs, the payment/time ratio tends to be significantly higher with CDs, thus tilting their preference towards the latter ${ }^{[36]}$. 
The findings in the literature support the concerns of public health professionals that in Brazil, in both private and public sectors, women are more likely to undergo unnecessary CD mainly due to the provider's preferences. Thus, supplierinduced demand seems to be a key determinant of the high incidence of Cesarean sections in Brazil.

\section{Case conclusion and policy recommendations to reduce Cesarean deliveries}

The experiences of China and Brazil, two large and fast growing middle-income countries, show that there are demand side and supply-side factors driving the high rate of unnecessary Cesarean sections. Cultural factors, such as fear of child birth and labor pain is observed among women both in China and Brazil ${ }^{[49]}$ in the wake of medicalization of birthing that promotes an invasive approach. In addition, women's perceptions in both countries that CD is safer for them and their children and that it ensures a higher quality of care is shaped by their interaction with their social network of families, friends, as well as with physicians.

The complex principal-agent like relationship between physicians and patients makes it difficult to say who the ultimate decision-maker is or how the decision has been reached in the end. The evidence from the literature shows that despite patients' own preferences, physicians can indeed induce patients' demand and change their choices. This is supported by the findings that the majority of both Chinese and Brazilian women at the start of their pregnancy have a preference for VD but changed their preference to $\mathrm{CD}$ after repeated interaction with their health care providers. Supplier-induced demand does seem to be a key determinant of the high incidence of Cesarean deliveries in both countries.

A moral hazard-type of factor may also help explain the high rates of Cesarean deliveries. With the presence of health insurance, financial considerations become less relevant in the choice between VD and CD. In such a context, cultural and personal preferences of physicians as well as patients, influence by the peers and families tend to assume more important roles in the definition of the types of procedure that will be followed. This problem is exacerbated in an environment where clear clinical guidelines are lacking, and the hidden preferences of providers tend to become the driving force. Time flexibility, fear of litigation and higher certainty, all these factors play a role in shaping providers' preferences. In addition, financial incentives generated by payment mechanisms are also an important determinant of the high rates of unnecessary CDs, particularly in the case of China where fee-for-service is still the main form of payment and, in public hospitals, the bonuses received by physicians are directly associated with the department's revenues.

Two broad categories of recommendation emerge from the evidence gathered from the literature: 1) demand-side interventions that empower and educate women, thus providing them with greater options for birthing; and 2) supply-side interventions implemented via i) changing physician's behavior using the best practices in maternal health and delivery, guided by the paradigm of quality of care, and ii) large scale policy interventions introduced at the national or subnational levels reforming payment mechanisms. These recommendations and interventions are guided by the works of researchers reporting quantitative as well as qualitative studies and large scale policy interventions undertaken by the Ministries of Health in China and Brazil.

\subsection{Demand-side interventions}

Education of physicians and patients about the risk of birthing procedures and CDs will not be able to change behavior if the social and cultural determinants of Cesarean deliveries are not understood. If the prevalent culture associates CDs with higher quality of care and regards it as a symbol of social status, any interventions aimed at reducing CDs must change the

social perception of birthing and increase the quality of care during labor for women of all social classes ${ }^{[44,49]}$. The National Campaign for "Humanization of Normal Childbirth and Reduction of Unnecessary Cesareans" introduced in 2006 in Brazil is one such example and it's ability to reduce CDs will be seen in the coming years. 
The mother's fear of labor pain can be addressed by the creation of "fear clinics", such as the ones that exist in the Netherlands, and by the introduction of the "birthing companion" implemented in several developed countries. These interventions are recent, but even in their early stages they have shown promising results in terms of influencing the demand for CD. In Taiwan, education interventions to reduce CD target first-time mothers who plan to have a VD and ignore women who have had a previous $\mathrm{CD}$. Education and behavioral change intervention programs must be designed to address the needs of all women including women who had a previous $\mathrm{CD}^{[50]}$.

\subsection{Supply-side interventions}

\subsubsection{Physicians behavior and practices}

Physicians' behaviors and practice differ extensively both within and between health care systems. Based on the literature for evidence-based interventions to reduce $\mathrm{CD}$, the various strategies aimed at changing physicians' behavior can be grouped into i) feedback and audit, and ii) quality of care interventions (in addition to the more multifaceted approaches) ${ }^{[51]}$. Feedback and audit are mainly achieved by mandatory second opinions ${ }^{[52]}$, internal and external peer review of medical records for trial of labor outcome, Vaginal Birth After Cesarean (VBAC), births outcomes and results sharing ${ }^{[53,54]}$.

A “mandatory second opinion to reduce unnecessary Cesarean sections" intervention trial was conducted in Brazil and five other Latin American countries ${ }^{[55]}$. It required by policy that all physicians deciding a non-emergency CDs to have a second opinion from a peer about the procedure before performing it. This intervention shows a very small difference between the CD rate before and after the intervention. It made an overall small reduction in CD rates but did not achieve the set target of $25 \%$ reduction. Though it was a multi-center study, its application in the private health care settings is limited because the trial was conducted in the public health system.

In Taiwan, a similar intervention comprised of a "peer reviewed Cesarean surveillance system" and a trial of labor for women who have had a previous CD was introduced at Taipei Veterans General Hospital. The intervention showed a reduction in CD rates from $21.3 \%$ to $17.8 \%$ and from $37 \%$ to $30.7 \%$ among first time mother and total CDs respectively during a four year period ${ }^{[53]}$. These experiences seem to indicate that substantial changes in physician's practices cannot be achieved through a single behavior intervention. Large reductions in CD rates seem to require more comprehensive set of interventions. The medical practices that have proven to be most effective in reducing $C D$ and that address both the medical aspects of delivery and provider behaviors are given in the Table, adapted from the study done by Haddad et al. ${ }^{[37]}$.

Table. Best medical practices to reduce cesarean deliveries

\begin{tabular}{ll}
\hline Number & Medical Interventions to Reduce Cesarean Deliveries \\
\hline 1 & Definition of precise indication of Cesarean \\
2 & Use of protocols and evidence-based flow charts \\
3 & Second opinion prior to Cesarean \\
4 & Encouragement of Vaginal Birth after Cesarean VBAC \\
5 & Effective induction of Labor and VBAC \\
6 & Monitoring labor to identify risk and promote natural birth \\
7 & WHO guidelines for labor management \\
8 & Mechanisms to combat pain and support women for fear of labor pains \\
9 & Fetal monitoring \\
10 & Training of medical professionals for non-surgical intervention to assist labor \\
\hline
\end{tabular}




\subsubsection{Training and supply of midwives}

As discussed earlier, shortage of midwives in China makes physicians even more hesitant to choose natural delivery method for women ${ }^{[7,11]}$. This is different from many developed countries like the UK and the Scandinavian welfare states, where trained midwifery programs are fully functional. The CDs for these countries are among the lowest in Europe at $22 \%$ for UK, $17 \%$ for Sweden, $16.6 \%$ for Norway and $16.3 \%$ for Finland ${ }^{[56]}$. China has introduced its first midwife led normal birth unit (MNBU) as an innovative policy approach to the CD epidemic in the country. The ongoing action research project at Nursing College Hangzhou Normal University resulted in the first MNBU in 2008. Evaluation results for the first 266 women accessing the service have been reported and are very encouraging. Among the women accessing the MNBU, $87.6 \%$ had VD compared to $58.8 \%$ for the women attending the standard care unit ${ }^{[57]}$. Even though this is a pilot project based in Hangzhou, China, its components could be replicated in other parts of the country. However, before an expansion should be done with caution, as additional regulatory measures might be needed to ensure the quality of the services. Despite this cautionary point, it should be noted that this intervention could be a potentially positive step towards reorganizing obstetric care and humanizing birthing practices in the country. In Brazil, physicians are the only professional that can attend delivery. Restructuring obstetric care policies in Brazil would allow women more choices and move towards a more humanized birthing process.

\subsubsection{Reforming payment mechanisms}

Payment mechanisms to physicians and hospitals have also been shown to be one of key elements in multifaceted approaches that have proven effective in reducing CD rates in some cases ${ }^{[58,59]}$.

In Taiwan, in order to control costs, the NHI changed its reimbursement mechanisms from fee-for-service to a case-based payment system. The NHI reduced the reimbursement differences between CDs and VDs to limit physicians' financial incentive to perform CDs ${ }^{[26]}$. Reimbursement for complicated cases is based on a fee-for-service scheme, but the total percentage of fee-for-service cases per provider cannot exceed a ceiling set by the Bureau. This payment method was designed to increase health care providers' cost consciousness and reduce unnecessary CD. Similarly, in Brazil's public health sector payment for $\mathrm{CD}$ is virtually the same as $\mathrm{VD}{ }^{[33]}$, which might partially attribute to the lower $\mathrm{CD}$ rates compared to the private sector.

Pay for performance has been used in developing countries to reward health care providers to achieve results. This is particularly used in maternal and child health services and has proven to increase the uptake of prenatal and postnatal checkups and children's immunization rates ${ }^{[60]}$. A similar rationale could also be applied to control for unnecessary high CD rates by setting a $C D$ rate target and reward physicians or institutions if the $C D$ is kept at or close below the target level. The risk is that physicians or hospitals might select the less complicated cases in order to achieve the target. Therefore, more careful thinking on the design and implementation is required.

\section{A call to reduce elective surgeries in the movement towards Universal Health Coverage}

This paper shows that the causes for the high rate of CDs are many, and include both supply and demand factors. Despite the multi-causal nature of the problem and the fact that the individual mother's interest to choose her way of delivery is paramount in the case of $\mathrm{CD}$, the evidence also suggests that physicians play a critical role in determining high CDs. While acknowledging patients' preferences, the government and health insurance can certainly influence physicians' and patients' behaviors to more consciously choose more cost-effective options. Therefore, in a context in which countries are trying to achieve UHC, the evidence presented in this paper supports the call for implementing complementary policy interventions and regulation on the health service delivery side to ensure minimal efficiency loss due to resources being diverted to unnecessary procedures or hospital stays. 


\section{Acknowledgement}

This paper has greatly benefited from discussions with Maria Luisa Escobar and Joy de Beyer.

As usual, the findings, interpretations, and conclusions expressed in this paper are entirely those of the authors and should not be attributed in any manner to the World Bank, to its affiliated organizations, or to members of its Board of Executive Directors or the countries they represent.

\section{References}

[1] Chou, R., et al. Diagnostic imaging for low back pain: advice for high-value health care from the American College of Physicians. Annals of Internal Medicine. 2011; 154(3): 181-189. PMid: 21282698. http://dx.doi.org/10.7326/0003-4819-154-3-201102010-00008

[2] Wulff, K.C., F.G. Miller, S.D. Pearson. Can coverage be rescinded when negative trial results threaten a popular procedure? The ongoing saga of vertebroplasty. Health affairs (Project Hope). 2011; 30(12): 2269-2276. PMid: 22147854. http://dx.doi.org/10.1377/hlthaff.2011.0159

[3] Souza, J.P., et al. Caesarean section without medical indications is associated with an increased risk of adverse short-term maternal outcomes: the 2004-2008 WHO Global Survey on Maternal and Perinatal Health. BMC medicine. 2010; 8(Journal Article): 71.

[4] Althabe, F., J.M. Belizan. Caesarean section: the paradox. Lancet. 2006; 368(9546): 1472-1473. http://dx.doi.org/10.1016/S0140-6736(06)69616-5

[5] Wilmink, F., et al. Neonatal outcome following elective cesarean section beyond 37 weeks of gestation: a 7-year retrospective analysis of a national registry. Am J Obstet Gynecol. 2010; 202(3): 250.e1-8.

[6] Ribeiro, V.S., et al. Why are the rates of cesarean section in Brazil higher in more developed cities than in less developed ones? Brazilian journal of medical and biological research = Revista brasileira de pesquisas medicas e biologicas / Sociedade Brasileira de Biofisica ...[et al.]. 2007; 40(9): 1211-1220.

[7] Wang, B., et al. National survey on midwifery practice in health facilities in China. Zhonghua fu chan ke za zhi. 2007; 42(5): 305-308. PMid: 17673041.

[8] Xie, R.H., et al. Cesarean Section and Postpartum Depression in a Cohort of Chinese Women with a High Cesarean Delivery Rate. Journal of women's health (2002), 2011(Journal Article).

[9] Organization, W.H., Appropriate technology for birth. Lancet. 1985; 2(8452): 436-7.

[10] Gibbons, L., et al. The Global Numbers and Costs of Additionally Needed and Unnecessary Caesarean Sections Performed per Year:Overuse as a Barrier to Universal Coverage. 2010; World Health Organization.

[11] McCallum, C. Explaining caesarean section in Salvador da Bahia, Brazil. Sociology of health \& illness. 2005; 27(2): $215-242$. PMid: 15787776. http://dx.doi.org/10.1111/j.1467-9566.2005.00440.x

[12] Tang, S., X. Li, Z. Wu. Rising cesarean delivery rate in primiparous women in urban China: evidence from three nationwide household health surveys. American Journal of Obstetrics and Gynecology. 2006; 195(6): 1527-1532. PMid: 16677593. http://dx.doi.org/10.1016/j.ajog.2006.03.044

[13] Klemetti, R., et al. Cesarean section delivery among primiparous women in rural China: an emerging epidemic. American Journal of Obstetrics and Gynecology. 2010; 202(1): 65.e1-65.e6.

[14] Lei, H., S.W. Wen, M. Walker. Determinants of caesarean delivery among women hospitalized for childbirth in a remote population in China. Journal of obstetrics and gynaecology Canada: JOGC = Journal d'obstetrique et gynecologie du Canada : JOGC. 2003; 25(11): 937-943. PMid: 14608444.

[15] Betran, A.P., et al. Rates of caesarean section: analysis of global, regional and national estimates. Paediatric and perinatal epidemiology. 2007; 21(2): 98-113. PMid: 17302638. http://dx.doi.org/10.1111/j.1365-3016.2007.00786.x

[16] Gerring, J. What is a Case Study and What is it Good for? American Political Science Review. 2004; 98(2): 341-354. http://dx.doi.org/10.1017/S0003055404001182

[17] Declercq, E., et al. Is a rising cesarean delivery rate inevitable? Trends in industrialized countries, 1987 to 2007. Birth (Berkeley, Calif.). 2011; 38(2): 99-104. PMid: 21599731. http://dx.doi.org/10.1111/j.1523-536X.2010.00459.x

[18] Aday, L.A., R. Andersen. A framework for the study of access to medical care Health Services Research. 1974; 9: 208-20. PMid: 4436074.

[19] Andersen, R. Revisiting the behavioral model and access to medical care: does it matter. Journal of Health and Social Behavior. 1995; 36(1): 1-10. http://dx.doi.org/10.2307/2137284

[20] Roberts, M.J., et al. Getting health reform right: a guide to improving performance and equity. 2004; Oxford University Press. 
[21] Yip, W., et al. Early appraisal of China's huge and complex health-care reforms. Lancet. 2012; 379(9818): 833-42. http://dx.doi.org/10.1016/S0140-6736(11)61880-1

[22] Feng, X.L., et al. Factors influencing rising caesarean section rates in China between 1988 and 2008. Bulletin of the World Health Organization. 2012; 90(1): 30-9, 39A.

[23] Sufang, G., et al. Delivery settings and caesarean section rates in China. Bulletin of the World Health Organization. 2007; 85(10): 755-762. PMid: 18038056. http://dx.doi.org/10.2471/BLT.06.035808

[24] Tsai Yw, H.T.W. National health insurance, physician financial incentives and primary cesarean deliveries in Taiwan. American Journal of Public Health. 2002; 92(9): 1514-7. http://dx.doi.org/10.2105/AJPH.92.9.1514

[25] Xiao, S., et al. Utilization of delivery care among rural women in China: does the health insurance make a difference? a cross-sectional study. BMC public health. 2010; 10(Journal Article): 695.

[26] Lo, J.C. Financial incentives do not always work-An exampleof cesarean sections in Taiwan. Health Policy. 2008; 88(Journal Article): 121-129.

[27] Lin, H.C., S. Xirasagar, Y.C. Tung. Impact of a cultural belief about ghost month on delivery mode in Taiwan. Journal of epidemiology and community health. 2006; 60(6): 522-526. PMid: 16698984. http://dx.doi.org/10.1136/jech.2005.041475

[28] Gama Ade, S., et al. Women's representations and experiences with vaginal and cesarean delivery in public and private maternity hospitals. Cadernos de saude publica/Ministerio da Saude, Fundacao Oswaldo Cruz, Escola Nacional de Saude Publica. 2009; 25(11): 2480-2488.

[29] Chu, K.H., et al. Women's preference for cesarean delivery and differences between Taiwanese women undergoing different modes of delivery. BMC health services research. 2010; 10(Journal Article): 138.

[30] Guo, S., et al. Delivery settings and caesarean section rates in China. Bulletin of the World Health Organization. 2007; 85(10): 755-762. http://dx.doi.org/10.2471/BLT.06.035808

[31] Hou, X., J. Coyne. The emergence of proprietary medical facilities in China. Health policy (Amsterdam, Netherlands). 2008; 88(1): 141-151. PMid: 18442867. http://dx.doi.org/10.1016/j.healthpol.2008.03.004

[32] Almeida, S., et al. Significant differences in cesarean section rates between a private and a public hospital in Brazil. Cadernos de saude publica / Ministerio da Saude, Fundacao Oswaldo Cruz, Escola Nacional de Saude Publica. 2008; 24(12): $2909-2918$. http://dx.doi.org/10.1590/S0102-311X2008001200020

[33] Barros, A.J., I.S. Santos, A.D. Bertoldi. Can mothers rely on the Brazilian health system for their deliveries? An assessment of use of the public system and out-of-pocket expenditure in the 2004 Pelotas Birth Cohort Study, Brazil. BMC health services research. 2008; 8(Journal Article): 57.

[34] Barros, F.C., J.P. Vaughan, C.G. Victora. Why so many caesarean sections? The need for a further policy change in Brazil. Health policy and planning. 1986; 1(1): 19-29. PMid: 10283013. http://dx.doi.org/10.1093/heapol/1.1.19

[35] Barros, F.C., et al. Epidemic of caesarean sections in Brazil. Lancet. 1991; 338(8760): 167-169. http://dx.doi.org/10.1016/0140-6736(91)90149-J

[36] Barros, A.J., et al. Patterns of deliveries in a Brazilian birth cohort: almost universal cesarean sections for the better-off. Revista de saude publica. 2011; 45(4): 635-643. PMid: 21670862. http://dx.doi.org/10.1590/S0034-89102011005000039

[37] Haddad Sel, M., J.G. Cecatti. Strategies directed to professionals for reducing unnecessary cesarean sections in Brazil. Revista brasileira de ginecologia e obstetricia : revista da Federacao Brasileira das Sociedades de Ginecologia e Obstetricia. 2011; 33(5): 252-262.

[38] Sakae, T.M., P.F. Freitas, E. d'Orsi. Factors associated with cesarean section rates in a university hospital. Revista de saude publica. 2009; 43(3): 472-480. PMid: 19448914.

[39] Mendoza-Sassi, R.A., et al. Risk factors for cesarean section by category of health service. Revista de saude publica. 2010; 44(1): 80-89. PMid: 20140332. http://dx.doi.org/10.1590/S0034-89102010000100009

[40] Potter, J.E., et al. Women's autonomy and scheduled cesarean sections in Brazil: a cautionary tale. Birth (Berkeley, Calif.). 2008; 35(1): 33-40. PMid: 18307486. http://dx.doi.org/10.1111/j.1523-536X.2007.00209.x

[41] Vogt, S.E., et al. Characteristics of labor and delivery care in three healthcare models within the Unified National Health System in Belo Horizonte, Minas Gerais State, Brazil. Cadernos de saude publica / Ministerio da Saude, Fundacao Oswaldo Cruz, Escola Nacional de Saude Publica. 2011; 27(9): 1789-1800. http://dx.doi.org/10.1590/S0102-311X2011000900012

[42] Begley, C.M. Consumer demand for caesarean sections in Brazil. Episiotomy rates may change after evidence based intervention. BMJ (Clinical research ed.). 2002; 325(7359): 335. PMid: 12173617. http://dx.doi.org/10.1136/bmj.325.7359.335

[43] Bettiol, H., et al. Consumer demand for caesarean sections in Brazil. Demand is affected by mothers' perception of good health care. BMJ (Clinical research ed.). 2002; 325(7359): 335. PMid: 12173616. http://dx.doi.org/10.1136/bmj.325.7359.335 
[44] Potter, J.E., K. Hopkins. Consumer demand for caesarean sections in Brazil. Demand should be assessed rather than inferred. BMJ (Clinical research ed.). 2002; 325(7359): 335. PMid: 12169516. http://dx.doi.org/10.1136/bmj.325.7359.335

[45] Mandarino, N.R., et al. Aspects related to choice of type of delivery: a comparative study of two maternity hospitals in Sao Luis, State of Maranhao, Brazil. Cadernos de saude publica / Ministerio da Saude, Fundacao Oswaldo Cruz, Escola Nacional de Saude Publica. 2009; 25(7): 1587-1596. http://dx.doi.org/10.1590/S0102-311X2009000700017

[46] Torloni, M.R., et al. Portrayal of caesarean section in Brazilian women's magazines: 20 year review. BMJ (Clinical research ed.). 2011; 342(Journal Article): d276.

[47] Faúndes A and C. JG. Which policy for Caesarian sections in Brazil? An analysis of trends and consequences. Health Policy Plan. 1993; 8: 33-42. http://dx.doi.org/10.1093/heapol/8.1.33

[48] Dias, M.A., et al. The decision of women for cesarean birth: a case study in two units of the supplementary health care system of the State of Rio de Janeiro. Ciencia \& saude coletiva. 2008; 13(5): 1521-1534. http://dx.doi.org/10.1590/S1413-81232008000500017

[49] Behague, D.P., C.G. Victora, F.C. Barros. Consumer demand for caesarean sections in Brazil: informed decision making, patient choice, or social inequality? A population based birth cohort study linking ethnographic and epidemiological methods. BMJ (Clinical research ed.). 2002; 324(7343): 942-945. PMid: 11964338. http://dx.doi.org/10.1136/bmj.324.7343.942

[50] Wang, H., U.L. Chung. An alternative in childbirth education: vaginal delivery following earlier cesarean delivery. Hu li za zhi The journal of nursing. 2004; 51(4): 66-69.

[51] Chaillet, N., A. Dumont. Evidence-based strategies for reducing cesarean section rates: a meta-analysis. Birth (Berkeley, Calif.). 2007; 34(1): 53-64. PMid: 17324180. http://dx.doi.org/10.1111/j.1523-536X.2006.00146.x

[52] Althabe, F., et al. Mandatory second opinion to reduce rates of unnecessary caesarean sections in Latin America: a cluster randomised controlled trial. Lancet. 2004; 363(9425): 1934-1940. http://dx.doi.org/10.1016/S0140-6736(04)16406-4

[53] Liang, W.H., et al. Effect of peer review and trial of labor on lowering cesarean section rates. Journal of the Chinese Medical Association : JCMA. 2004; 67(6): 281-286. PMid: 15366405.

[54] Robson, M.S., I.W. Scudamore, S.M. Walsh. Using the medical audit cycle to reduce cesarean section rates. American Journal of Obstetrics and Gynecology. 1996; 174(1 Pt 1): 199-205. http://dx.doi.org/10.1016/S0002-9378(96)70394-0

[55] Althabe, F., et al. Mandatory second opinion to reduce rates of unnecessary caesarean sections in Latin America: a cluster randomised controlled trial. The Lancet. 2004; 363(12): 1934-40. http://dx.doi.org/10.1016/S0140-6736(04)16406-4

[56] World Health Organization, European Regional Office Health for all data base. Accessed in December, 2013.

[57] Cheung, N.F., et al. Clinical outcomes of the first midwife-led normal birth unit in China: a retrospective cohort study. Midwifery. 2011; 27(5): 582-587. PMid: 21236528. http://dx.doi.org/10.1016/j.midw.2010.05.012

[58] Poma, P.A. Effect of departmental policies on cesarean delivery rates: a community hospital experience. Obstetrics and gynecology. 1998; 91(6): 1013-1018. http://dx.doi.org/10.1016/S0029-7844(98)00077-5

[59] Lagrew, D.C., Jr., M.A. Morgan. Decreasing the cesarean section rate in a private hospital: success without mandated clinical changes. American Journal of Obstetrics and Gynecology. 1996; 174(1 Pt 1): 184-191. http://dx.doi.org/10.1016/S0002-9378(96)70392-7

[60] Lagarde, M., T. Powell-Jackson, D. Blaauw. Managing incentives for health providers and patients in the move towards universal coverage. Background paper for the Global Symposium on Health Systems Research. 16-9 November 2010; Switzerland: Montreux. 